Slit-lamp examination before leaving hospital showed what appeared to be a healed corneal wound with still some folding (greatly reduced) of Dešcemet's membrane, a normal anterior chamber, the eye free from inflammation, vision $6 / 18$ and no apparent increase in the size of the original corneal opacity.

Summary.-A case of fistula or hole in the cornea is reported. Fluorescein is suggested as a confirmatory test in leaking corneal wounds and a method of treatment is described.

\title{
REFERENCES
}

1. DE SCHWEINIT2.-Diseases of the Eye, 10th Edition, p. 288.

2. Fuchs' Text-Book of Ophthalmology, 6th Edition (Duane), p. 265.

\section{AN OPERATION FOR ENTROPION OF TRACHOMA}

\author{
BY \\ MAJOR C. COCKBURN, R.A.M.C:
}

IT is to be noted that the operation described below is essentially a slight modification of that described by Busacca. (Arch. Ophthal., November 16, 1936).

As eye specialist to a Libyan prisoner-of-war camp during 1942, considerable experience in the treatment of trichiasis entropion has been gained, and it is considered justifiable to report on an operation which has been found to be most satisfactory.

About 60 cases, all Libyans, have been operated on. In all instances the disease had reached a chronic fibrotic stage with deformity of the upper tarsal plate and widespread trichiasis.

Anaesthesia.-Nerve block of supra-orbital and frontal nerves and local infiltration of eyelid with novotux and adrenalin.

A Desmarres' entropion forceps is carefully applied to the eyelid and the screw made firm to ensure adequate haemostasis. The skin is incised parallel to the lid margin and about $5 \mathrm{~mm}$. above it. On either side the skin is well undermined to expose the fibres of the orbicularis muscle. The lower lip is freed right down to the cilia. The muscle fibres are then excised exposing the white tarsal plate. It is wise to remove all fibro-fatty tissue from the surface of the plate to facilitate further procedures. A linear incision is then made in the tarsus close to and parallel to its lower margin, down to but not incising the conjunctiva. A similar linear incision is made about $2 \mathrm{~mm}$. above, and a strip of tarsal plate can then be readily excised. Even where the tarsal plate is thin, this procedure 


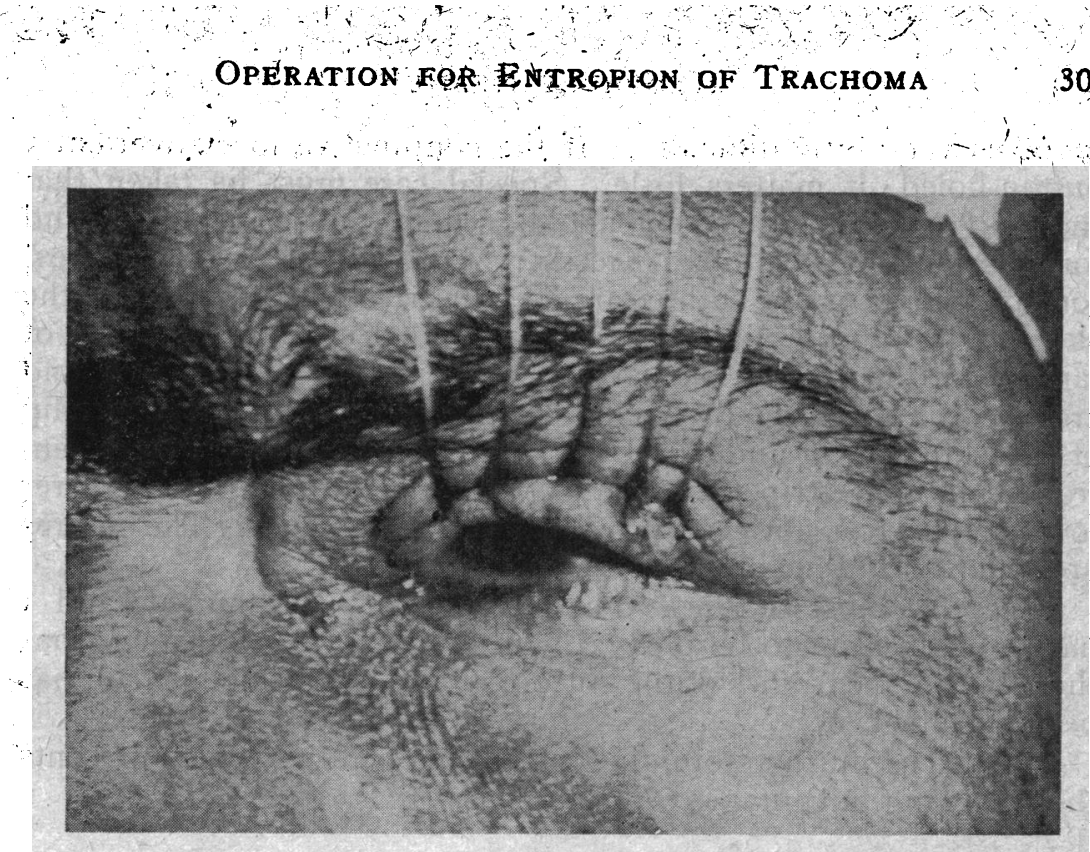

FIG. 1.

Photograph taken immediately after completion of operation, showing arrangement of sutures.

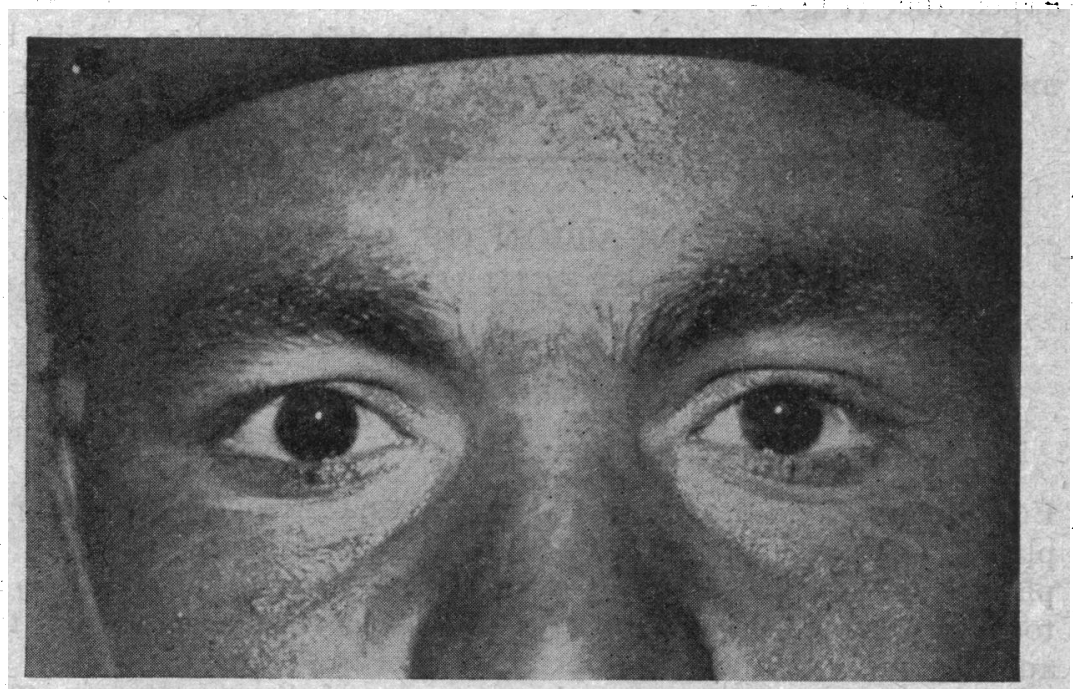

Fig. 2.

Operation nine months ago for trichiasis entropion both upper eyelids. 
involves very little difficulty. If the conjunctiva is inadvertently button-holed, it matters little. Special care must be taken that the strip of tarsus excised extends the whole width of the plate, and for this purpose it is often necessary to re-adjust the Desmarres' forceps. Four or five sutures are then inserted passing through the skin of the inferior lip of the wound and deep into upper lip of tarsus, and made taut. The ends of the sutures are left long and are fixed on the brow by sticking-plaster (Fig. 1). The upper lip of the skin flap.is undisturbed. Depending on the degree of entropion, a wide strip may be excised or the sutures placed nearer to the cilia. It is not necessary to bandage both eyes. The sutures are removed in four days.

Recently, most of these cases have been re-examined, and I have good reason to be pleased with results. In no instance has there been a recurrence of the entropion and the cosmetic result has been excellent.

It wotild seem, therefore, that here is an operation which presents the following advantages:-

1. It is easy to perform.

2. It gives a complete and permanent cure of entropion.

3. It gives an excellent cosmetic result. In fact the slight ptosis present in all these cases is rectified, giving a rather pleasing, alert appearance (Fig 2).

For these reasons, it is considered that this operation might be more widely known and practised.

\section{A MODIFICATION OF ARRUGA'S SPECULUM}

BY

\section{HUMPHREY NEAME}

LONDON

For operation on detachment of the retina, Arruga's speculum of plated metal was taken as a model and an instrument made of plastic material was designed $2 \mathrm{~mm}$. wider than the original, so as to give a larger field within the hollow of the retractor for the application of diathermy in detachment of the retina.

The figure shows the general appearance of the speculum. The plastic material is roughened for a small area on its convex surface and for a larger area in the hollow of the concave side. Light enters from a small battery or through a transformer from the main 